\title{
Ligamentotaxis versus Open Reduction and Internal Fixation for Distal Radius Intra-Articular Fractures
}

\author{
Mahmoud Abdel-Ghany, Tohamy Goudah Tohamy, Wael M. Shaaban, \\ Abdel-Hamied A. Atallah, Tharwat M. Abdel-Rahman \\ Orthopedic and Trauma Surgery, Al-Azhar University, Cairo, Egypt \\ Email: mhghany@hotmail.com, tohamy24@yahoo.com,waelsh72@hotmail.com, joints@abdelhamid.net, \\ tharwatakied@gmail.com
}

How to cite this paper: Abdel-Ghany, M., Tohamy, T.G., Shaaban, W.M., Atallah, A.-H.A. and Abdel-Rahman, T.M. (2017) Ligamentotaxis versus Open Reduction and Internal Fixation for Distal Radius IntraArticular Fractures. Open Journal of Orthopedics, 7, 21-31.

http://dx.doi.org/10.4236/ojo.2017.71004

Received: November 9, 2016

Accepted: January 22, 2017

Published: January 25, 2017

Copyright $\odot 2017$ by authors and Scientific Research Publishing Inc. This work is licensed under the Creative Commons Attribution International License (CC BY 4.0).

http://creativecommons.org/licenses/by/4.0/

(c) (i) Open Access

\begin{abstract}
Objectives: This study compared the clinical and radiological outcomes of two different methods for the treatment of distal radial intra-articular fractures. Patients and Methods: Forty-six patients with distal radius intra-articular fractures were divided into two groups. Group I included 24 patients with type $\mathrm{C}$ fracture treated by external fixator augmented by percutaneous K-wires. Group II included 22 patients with type $\mathrm{C}$ fracture treated by volar locked distal radial plate augmented by K-wires. Two patients had complex injuries necessitating double plating (sandwich). All patients were evaluated clinically by Mayo Wrist Score and radiologically by Sarmiento's radiological score. Results: Both groups reported good personal satisfaction according to Mayo Wrist Score, and the results were not statistically different between the two groups. In Group I, 19 patients (79.2\%) had excellent radiological outcome and five patients (20.9\%) had good radiological outcome according to Sarmiento's radiological score. In Group II, 20 patients (90.9\%) had excellent outcome, and two (9.1\%) had good radiological outcome; there was no or insignificant deformity. Conclusions: Complex distal radial fractures can be treated either by external fixation (ligamentotaxis) or by locked pre-contoured plating. The clinical outcome of plating and external fixator in our study did not show any statistically significant difference. The radiological outcome had no correlation with the clinical outcome.
\end{abstract}

\section{Keywords}

Distal Radial Fracture, Complex Fracture of Distal Radius, External Fixator, Locked Volar Plate 


\section{Introduction}

Intra-articular fractures of the distal radius represent a therapeutic challenge compared to unstable extra-articular fractures [1]. These fractures can be managed either by external fixation with Kirschner wire (K-wire) [2] or by open reduction and internal fixation (ORIF) using volar fixed angle locked plate, which is also used for treating unstable fractures [3] [4]. Clinical outcome of the distal radius fractures (limited range of motion, reduced grip strength, and radiographic abnormalities) does not always reflect the pain and disability of the injured wrist [5] [6].

The purpose of this study was to compare the clinical and radiological outcomes of the treatment of intra-articular distal radial fractures by external fixator with $\mathrm{K}$-wire versus open reduction and internal fixation using distal radius locked plate.

\section{Patients and Methods}

All patients included in this study had signed consent to be enrolled in this study and ethical committee of our institution had an agreement for this work

This multicentre, retrospective study included 46 patients aged below 50 years, who had intra-articular distal radial fractures. All patients are active working and have no chronic diseases (Hypertension, Diabetes, renal or liver diseases). All patients had been treated either by external fixator (ligamentotaxis) augmented by percutaneous $\mathrm{K}$-wires or by ORIF using distal radius locked plate. Twentyfour patients (52.2\%) were treated by external fixator (ligamentotaxis) using K-wires (Group I) and 22 patients (47.8\%) were treated by ORIF using distal radius locked plate (Group II).

Group I included 24 patients (52.2\%); 20 were male patients (83.3\%) and four were female patients (16.7\%); their age ranged from 23 to 47 years, with a mean age of 32.1 years. Fractures were classified according to Müller (AO) classification as type C2 $(n=3,12.5 \%)$, and type C3 $(n=21,87.5 \%)$. Reasons for fracture were motor vehicle accident in 19 patients $(79.2 \%)$, and fall from height in five patients (20.8\%). There were 23 dominant hand fractures (95.8\%) and one bilateral hand fracture (4.2\%). Distal Radio Ulnar Joint (DRUJ) dissociation was observed in 11 patients (45.8\%), and was more frequently sustained by those involved in high velocity motor vehicle accidents. Associated injuries were recorded in the form of spinal fracture and lower limb fracture in five patients (20.8\%), and were managed by the same medical team at the same study center (Table 1).

Group II included 22 patients (47.8\%); their age ranged from 21 to 47 years, with a mean age of 35.8 years. There were 19 male patients $(86.4 \%)$ and three female patients (13.6\%). Eighteen fractures (81.8\%) were type C3 and four fractures (18.2\%) were type C2. Reasons for injury were fall from height in three patients (13.6\%) and motor vehicle accident in 19 patients (86.4\%). All patients had dominant hand fracture, with no bilateral fractures or associated injuries. DRUJ injuries were observed in 14 patients (63.6\%). 
Table 1. Demographic data for both groups.

\begin{tabular}{|c|c|c|c|c|c|c|c|c|c|}
\hline $\begin{array}{c}\text { Pt. } \\
\text { Group I }\end{array}$ & Age & Sex & $\begin{array}{l}\text { Dom. } \\
\text { Hand }\end{array}$ & $\begin{array}{l}\text { Type of } \\
\text { fracture }\end{array}$ & Group & Age & Sex & $\begin{array}{c}\text { Fracture } \\
\text { type }\end{array}$ & $\begin{array}{l}\text { Dom. } \\
\text { Hand }\end{array}$ \\
\hline 1 & 22 & Male & Rt. & $\mathrm{C} 3$ & & 43 & Male & $\mathrm{C} 2$ & Rt. \\
\hline 2 & 24 & Male & Rt. & $\mathrm{C} 3$ & & 28 & Male & $\mathrm{C} 3$ & Rt. \\
\hline 3 & 36 & Male & Rt. & $\mathrm{C} 2$ & & 34 & Male & $\mathrm{C} 3$ & Rt. \\
\hline 4 & 27 & Male & Rt. & $\mathrm{C} 3$ & & 21 & Male & $\mathrm{C} 3$ & Rt. \\
\hline 5 & 34 & Male & Rt. & $\mathrm{C} 3$ & & 35 & Female & C3 & Rt. \\
\hline 6 & 26 & Male & Rt. & $\mathrm{C} 3$ & & 39 & Male & $\mathrm{C} 3$ & Rt. \\
\hline 7 & 33 & Male & Rt. & C3 & & 26 & Male & $\mathrm{C} 2$ & Rt. \\
\hline 8 & 44 & Male & Rt. & $\mathrm{C} 2$ & & 36 & Male & C3 & Rt. \\
\hline 9 & 39 & Male & Rt. & $\mathrm{C} 3$ & & 22 & Male & $\mathrm{C} 2$ & Rt. \\
\hline 10 & 37 & Female & Rt. & $\mathrm{C} 3$ & & 28 & Male & $\mathrm{C} 3$ & Rt. \\
\hline 11 & 25 & Male & Rt. & $\mathrm{C} 3$ & & 34 & Male & $\mathrm{C} 3$ & Rt. \\
\hline 12 & 36 & Male & Rt. & $\mathrm{C} 2$ & Group II & 42 & Male & C3 & Rt. \\
\hline 13 & 47 & Female & Rt. & C3 & $=22 \mathrm{pts}$ & 46 & Female & C3 & Lt. \\
\hline 14 & 28 & Male & Rt. & C3 & & 47 & Male & C3 & Rt. \\
\hline 15 & 36 & Male & Rt. & C3 & & 39 & Male & C3 & Rt. \\
\hline 16 & 28 & Male & Rt. & C3 & & 39 & Male & C3 & Rt. \\
\hline 17 & 40 & Male & Rt. & $\mathrm{C} 3$ & & 40 & Male & $\mathrm{C} 2$ & Rt. \\
\hline 18 & 23 & Male & Bilat. & C3 & & 28 & Male & C3 & Rt. \\
\hline 19 & 20 & Female & Rt. & $\mathrm{C} 3$ & & 44 & Female & C2 & Rt. \\
\hline 20 & 43 & Male & Rt. & $\mathrm{C} 3$ & & 30 & Male & $\mathrm{C} 3$ & Rt. \\
\hline 21 & 27 & Male & Rt. & C3 & & 45 & Male & C3 & Rt. \\
\hline 22 & 29 & Female & Rt. & $\mathrm{C} 2$ & & 41 & Male & C3 & Rt. \\
\hline 23 & 31 & Male & Rt. & $\mathrm{C} 3$ & & & & & \\
\hline 24 & 36 & Male & Rt. & $\mathrm{C} 2$ & & & & & \\
\hline
\end{tabular}

\section{Methods}

Group I: The surgical technique for all the patients of this group was the same and was performed by the same surgical team. All fractures were characterized by disfigurement of the articular surface, bone loss, and shortening of the affected radius. After reduction, the application of the fixators was in the dorsal plane. Pins were inserted through small incisions, two proximal to the fracture in the distal radius and two distal in the shaft of the second metacarpal bone. These pins were inserted at an angle of $60^{\circ}$ to the horizontal plane. Augmentation with $\mathrm{K}$-wires was required in majority of the cases in order to hold the provisionally restored articular fragments. The reduction was monitored and confirmed by fluoroscopy (Figure 1). DRUJ instability (DRUJI) was checked intra- 
operatively by manual testing after completion of the surgery in all cases. We reduced radioulnar joint injury for 11 patients (45.8\%) by using medial K-wire, and if the joint was still instable, the transfixing wire through DRUJ was retained for 6 weeks. The external fixator frames were removed after 6 to 8 weeks for all patients; however K-wires were not removed until complete consolidation of the fractures occurred. Wrist joint mobilization was allowed after removal of the external fixator frame, regardless of the removal of the wire or its retention until 2 weeks. Group II: The patients of this group were treated by ORIF using distal volar radial locked plate. After reduction, K-wires were placed through the radial styloid provisionally, if required. An anterior locking plate was then positioned. All the plates were precontoured for anterior flare of the distal radius. The plate position was adjusted based on intra-operative fluoroscopy finding. The plate position was verified in both anteroposterior (AP) and lateral planes before the distal screws were placed. Among the cases where the distal fragment was severely comminuted, the plate was adjusted as far as possible, but not farther beyond the watershed line of the radius. Double plating was used in two cases, as the screw caused disfigurement of the dorsal articular surface, which necessitated buttressing from the dorsal surface (Figure 2). DRUJ was checked manually after the surgery. After fixation of the distal radius, the distal end of the radius was grasped with the forearm in a neutral position, and the distal end of the ulna was grasped by the contra-lateral hand by moving distal ulna from the dorsal to the palmar direction. If there was a translation of 5 to $10 \mathrm{~mm}$ as compared with the uninjured wrist, it was considered as DRUJI. Transverse wire through the DRUJ was inserted in 12 patients (54.5\%) who had significant DRUJI after plate fixation.

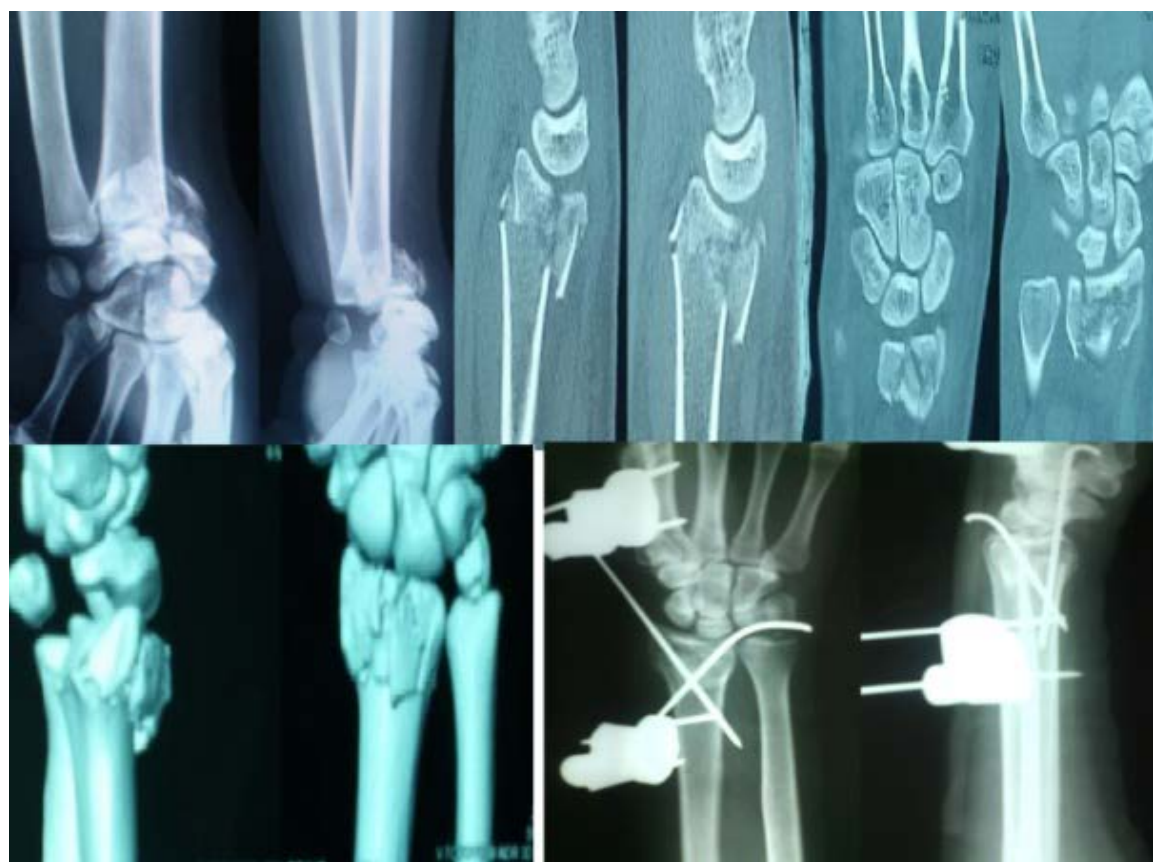

Figure 1. Intra-articular comminuted fracture distal radius treated by external fixator augmented by K-wire. 


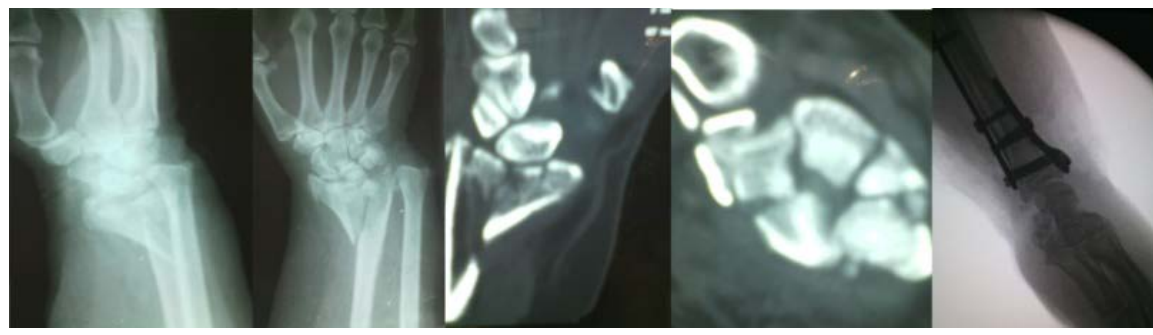

Figure 2. Intra-articular comminuted fracture distal radius treated by sandwich double plating.

Post-operative care for the external fixator group was recommended to control pain and edema and to maintain the range of motion in the fingers, elbow, and shoulder. All patients were encouraged to perform their routine activities by themselves, to the extent possible.

For internal fixation plate group, the splint below the elbow was retained for at least 6 weeks post-operatively. These patients were treated with medication to control pain and edema for 2 weeks. After the removal of the splint, they were encouraged to move the elbow and shoulder with passive motion of the wrist. After 8 weeks, the patients were encouraged to perform their daily activities entirely by themselves.

\section{Results}

All the patients were followed up clinically and radiologically 12 - 26 months with average 17.4 months (Table 2). Mayo Wrist Scoring System was used for clinical evaluation of both groups (Table 3); Sarmiento's radiological score was used for radiological evaluation [7]. All patients were followed up from 12 - 24 months (average 17.3 months).

\section{Statistical Analysis}

Statistical analyses of data were performed using SPSS 15 and PASTA software.

Group I: The mean score for pain at the last follow-up was $23.9 \pm 2.0$; the mean score for satisfaction was $23.1 \pm 2.4$; the mean grip strength was $17.29 \pm$ 4.6; the mean value for the range of motion (ROM) was $16.8 \pm 4.3$; the mean score representing the final outcome was $82.2 \pm 9.2$.

Group II: The mean score for pain at the last follow-up was $24.09 \pm 1.9$; the mean score for satisfaction was $23.6 \pm 2.2$; the mean grip strength was $20.4 \pm 5.9$; the mean value for ROM was $18.6 \pm 4.9$; the mean score for the final outcome was $87.04 \pm 6.6$.

The final clinical outcome, according to Mayo wrist Score, is classified as follows: $90-100=$ Excellent, $80-89=$ Good, $65-79=$ Fair, and less than $65=$ Poor (Table 4).

T-test was used to compare the two groups and there were no significant differences for pain $(P=0.74)$, satisfaction $(P=0.076)$, ROM $(P=0.856)$, and the grip strength $(\mathrm{P}=0.805)$. Correlation analysis showed that personal satisfaction was not correlated with final outcome among patients of both groups (Table 5), 
Table 2. Follow up at different periods for both groups.

\begin{tabular}{|c|c|c|c|c|c|c|c|}
\hline \multirow{2}{*}{$\begin{array}{l}\text { Group I } \\
\mathrm{N}^{*}=24\end{array}$} & \multicolumn{3}{|c|}{ Mean Follow Up } & \multirow{2}{*}{$\begin{array}{l}\text { Group II } \\
\mathrm{N}^{*}=22\end{array}$} & \multicolumn{3}{|c|}{ Mean Follow Up } \\
\hline & Min & $\max$ & Mean \pm SD & & Min & $\max$ & Mean \pm SD \\
\hline F-up at $6 \mathrm{~ms}$ & 35 & 70 & $53.3 \pm \mathrm{SD} 9.3$ & & 22 & 65 & $95 \pm$ SD 7.4 \\
\hline F-up at $12 \mathrm{~ms}$ & 55 & 90 & $71.4 \pm$ SD 10.1 & & 22 & 75 & $100 \pm S D 7.2$ \\
\hline F-up at $24 \mathrm{~ms}$ & 60 & 100 & $82.9 \pm$ SD 10.5 & & 22 & 75 & $100 \pm$ SD 8.2 \\
\hline
\end{tabular}

Table 3. Mayo Wrist scoring for the two groups.

\begin{tabular}{|c|c|c|c|c|c|c|c|c|c|c|}
\hline \multirow{2}{*}{ ID } & \multicolumn{5}{|c|}{ External Fixator (Group I), n = 24} & \multicolumn{5}{|c|}{ ORIF (Group II), $\mathrm{n}=22$} \\
\hline & Pain & Satisfaction & $\mathrm{ROM}^{*}$ & $\begin{array}{c}\text { Grip } \\
\text { Strength }\end{array}$ & $\begin{array}{c}\text { Final } \\
\text { outcome }\end{array}$ & Pain & Satisfaction & ROM & $\begin{array}{c}\text { Grip } \\
\text { Strength }\end{array}$ & $\begin{array}{c}\text { Final } \\
\text { outcome }\end{array}$ \\
\hline 1 & 20 & 20 & 15 & 15 & $65-79$ & 20 & 20 & 15 & 25 & $80-89$ \\
\hline 2 & 25 & 25 & 25 & 15 & $90-100$ & 25 & 25 & 25 & 15 & $90-100$ \\
\hline 3 & 25 & 20 & 15 & 15 & $65-79$ & 25 & 20 & 15 & 25 & $80-89$ \\
\hline 4 & 25 & 25 & 15 & 15 & $80-89$ & 25 & 25 & 25 & 15 & $90-100$ \\
\hline 5 & 25 & 25 & 15 & 15 & $80-89$ & 25 & 25 & 15 & 25 & $90-100$ \\
\hline 6 & 20 & 20 & 15 & 15 & $65-79$ & 25 & 25 & 25 & 25 & $90-100$ \\
\hline 7 & 25 & 25 & 15 & 15 & $80-89$ & 25 & 20 & 15 & 15 & $65-79$ \\
\hline 8 & 25 & 25 & 15 & 25 & $90-100$ & 25 & 25 & 15 & 25 & $90-100$ \\
\hline 9 & 25 & 25 & 25 & 25 & $90-100$ & 25 & 25 & 15 & 15 & $80-89$ \\
\hline 10 & 25 & 25 & 15 & 25 & $90-100$ & 25 & 25 & 15 & 25 & $90-100$ \\
\hline 11 & 25 & 25 & 15 & 25 & $90-100$ & 25 & 25 & 25 & 15 & $90-100$ \\
\hline 12 & 20 & 20 & 15 & 15 & $65-79$ & 20 & 25 & 15 & 25 & $80-89$ \\
\hline 13 & 25 & 25 & 25 & 15 & $90-100$ & 25 & 20 & 15 & 15 & $65-79$ \\
\hline 14 & 25 & 20 & 25 & 15 & $80-89$ & 20 & 20 & 25 & 25 & $90-100$ \\
\hline 15 & 25 & 25 & 15 & 15 & $80-89$ & 25 & 25 & 15 & 25 & $90-100$ \\
\hline 16 & 25 & 20 & 15 & 15 & $65-79$ & 25 & 20 & 15 & 25 & $80-89$ \\
\hline 17 & 25 & 25 & 15 & 25 & $90-100$ & 25 & 25 & 25 & 25 & $90-100$ \\
\hline 18 & 25 & 20 & 15 & 15 & $65-79$ & 20 & 25 & 15 & 25 & $80-89$ \\
\hline 19 & 25 & 25 & 15 & 15 & $80-89$ & 25 & 25 & 15 & 15 & $80-89$ \\
\hline 20 & 25 & 25 & 15 & 25 & $90-100$ & 25 & 25 & 25 & 15 & $90-100$ \\
\hline 21 & 25 & 25 & 25 & 15 & $90-100$ & 25 & 25 & 15 & 15 & $80-89$ \\
\hline 22 & 20 & 20 & 15 & 15 & $65-79$ & 25 & 25 & 25 & 15 & $90-100$ \\
\hline 23 & 25 & 25 & 15 & 15 & $80-89$ & & & & & \\
\hline 24 & 20 & 20 & 10 & 10 & $<65$ & & & & & \\
\hline
\end{tabular}

${ }^{*} \mathrm{ROM}=$ Range of motion. 
Table 4. Mayo wrist score.

\begin{tabular}{cccc}
\hline Group I $(\mathrm{n}=24)$ & Patients & Group II $(\mathrm{n}=22)$ & Patients \\
\hline Excellent $(90-100)$ & 9 & Excellent $(90-100)$ & 12 \\
Good $(80-89)$ & 7 & Good $(80-89)$ & 8 \\
Fair $(65-79)$ & 7 & Fair $(65-79)$ & 2 \\
Poor $(<65)$ & 1 & Poor $(<65)$ & 0 \\
\hline
\end{tabular}

Table 5. Results of correlation analysis for Mayo Wrist Score for the two groups.

\begin{tabular}{ccccccc}
\hline Item & $\mathrm{n}$ & $\begin{array}{c}\text { Correlation } \\
\text { coefficient }\end{array}$ & Sig. & $\mathrm{n}$ & $\begin{array}{c}\text { Correlation } \\
\text { coefficient }\end{array}$ & Sig. \\
\hline Pain & 0.389 & 0.074 & & -1.000 & 0.329 \\
Satisfaction & & 0.386 & 0.076 & & 0.386 & 0.076 \\
ROM & 24 & 0.041 & 0.856 & 22 & -1.821 & 0.083 \\
Grip Strength & & -0.056 & 0.805 & & 1.516 & 0.144 \\
Final outcome & & -0.133 & 0.554 & & -0.133 & 0.554 \\
\hline
\end{tabular}

and the difference between the two groups was not statistically significant.

Analysis of Sarmiento's radiological score indicated that Group I had excellent radiological results in 19 cases (79.1\%), with 13 cases demonstrating no or insignificant deformity (54.1\%) and six cases (25\%) exhibiting either dorsal angulations or shortening $<3 \mathrm{~mm}$. Five cases $(20.8 \%)$ had good radiological outcome (two cases had slight deformity, two cases had dorsal angulations of $1-10^{\circ}$, and one case had shortening of $5 \mathrm{~mm}$.). Only one case (4.1\%) reported poor radiological outcome (average radial deviation of $23^{\circ}$ ) in this group.

In Group II, 20 cases (90.9\%) had excellent outcome, four cases (18.1\%) exhibited shortening of $<3 \mathrm{~mm}, 11$ cases (50\%) exhibited no or insignificant deformity, two cases $(9.1 \%)$ demonstrated dorsal angulation of $0^{\circ}$, and two cases (9.05\%) had shown a loss of radial deviation of $<4^{\circ}$. Two cases $(9.05 \%)$ had good radiological outcome, one case (4.5\%) had loss of radial deviation of $5-9^{\circ}$, and one case (4.5\%) had dorsal angulations of $9^{\circ}$.

\section{Discussion}

Distal intra-articular radial fractures are very common fractures that represent a therapeutic challenge when compared to unstable extra-articular fractures, and there is no clear consensus regarding their appropriate treatment. Patients' outcome may differ according to method of evaluation. To ensure comprehensive treatment of these fractures, medical attention should be extended beyond physical impairment and radiography, since the final outcome may also depend on the post fracture rehabilitation.

In this study, we treated two groups with intra-articular fractures either by external fixator augmented by K-wires (Group I) or by ORIF by using volar 
locked plates and K-wires (Group II). The decision for treatment depended on the surgeons' preferences and equipment availability at each study center.

According to the Mayo Wrist Scoring System used for evaluating the clinical outcome, significant differences did not exist for pain between the two groups in our study at the final follow-up $(\mathrm{P}=0.006)$.

McQueen [8] in his randomized, prospective study compared the effectiveness of non-bridging and bridging external fixator in restoring the normal anatomy, carpal alignment, and hand function for the treatment of intra articular distal radial fractures. He had conducted the evaluations immediately after the surgery and showed that non-bridging external fixation achieved significantly better radial length compared to bridging fixation. It was reported that the pain outcome measures between the bridging and non-bridging fixator were similar during the initial analysis and after 1 year of follow-up. There were no significant differences between both groups for the carpal pain at the final follow-up.

In evidence based medicine (EBM), the amount of pain among patients treated with external fixation compared to that among patients treated by closed reduction and casting did not show significant difference until the first year [9]. A consensus remains to be reached regarding the choice of bridging or non-bridging methods in the external fixator treatment for distal radial fractures. Atroshi et al. in 2006 reported that non-bridging external fixation had no clinically relevant advantage over wrist-bridging fixation, but was more effective in maintaining radial length [10].

Huang et al. [11] in their study, treated 70 cases of intra-articular fractures of the distal radius by closed reduction and external fixation using small AO external fixators. They recommended that bridging external fixation is a more suitable and reliable method for the management of intra-articular distal radial fractures than non-bridging fixation. They concluded that meticulous reduction and rigid fixation, achieved on treatment with small $\mathrm{AO}$ external fixator, are the key factors that contributed to the good final clinical outcomes observed in their study.

A prospective cohort study tried to predict the association of pain with age, gender, co-morbidity, level of education, and claim of compensation. This study also analyzed the correlation of clinical outcome to that of radiological outcome. The authors reported that the baseline characteristics of the patients and the injuries in extra-articular distal radial fractures had a minor role in predicting the patients likely to develop pain and disability after 1 year [12].

In the present study, we did not find any significant difference in the final outcome between the two groups, while evaluating the correlation of different parameters with the final outcome. This is in agreement with the results of the prospective, randomized study by Rosental et al. [13], where the final outcome of unstable comminuted distal radial fractures treated by open reduction and internal fixation using volar plates was compared with outcomes of using percutaneous K-Wires fixation. They found that there was no significant difference for 
the final outcome according to the DASH score. On the contrary, they concluded that the volar plate for the distal intra-articular radial fractures offered faster recovery for patients requiring a faster return to function after injury.

We did not observe any significant correlation between the radiological and clinical outcomes among patients in this study. The information regarding the factors influencing the final outcome among patients with intra-articular distal radial fractures is conflicting in the existing literature. This also implies that neither limitations to the fracture construct nor reliability of radiographic measurements were responsible for the limited prediction of the final outcome in the previous studies.

Kasapinova and Kamiloski [14] found no significant statistical correlation between the radiographic parameters and the patient-rated outcome (disability).

Some authors have studied whether factors such as age and sex would affect the final outcomes, as these factors play a major role in determining the bone mineral density (BMD) [12] [15]. Hollevoet et al. studied the correlation of clinical parameters with the bone mineral density to a greater extent compared to the radiological parameters. They suggested that osteoporosis may be one of the factors affecting the outcome of comminuted intra-articular distal radial fractures. In contrast, Dhainaut et al. did not observe any significant association between the reduced BMD of the cortical bone of the hand analyzed by digital radiography (DXR) and the risk of having an intra-articular or extra-articular fragility fracture in the distal radius. They concluded that the use of glucocorticoids may be responsible for the increase in the risk of having an intra-articular fracture, more than BMD, which can cause more severe fractures [16].

In our study, routine evaluation of the DRUJ and transfixing wire was performed for the cases that required attention in both groups. Reduction of the joints with transfixing wires improved the outcome, as it reduces the complications. DRUJ reduction is considered the cornerstone for the reduction of comminuted distal radial fracture. Injury of the DRUJ has been classified into high energy or low energy trauma according to Fernandez and Jupiter [17] classification Fernandez and Jupiter based their classification on two main parameters; they considered soft tissue injury and DRUJ injury as the main factors which affect the outcomes of treatment for intra-articular fractures of distal radius.

De la Torra et al. [18] studied 12 cases with type 1 DRCJI and reported that the surgically treated DRCJI cases did not have better outcome than non-surgically treated cases.

In our study, $10 \%$ of the ORIF group was treated with double plating (sandwich plate). Ring et al. [19] studied 25 patients who had complex comminution of both the articular surface and the metaphysis (Type C3.2) associated with distal radial fractures. They were treated by double plating method, and $96 \%$ of the cases reported either good or excellent results according to the rating system of Gartland and Werley.

Day et al. [20] reported the results of 12 patients who were treated by double plating, whose functional outcome were evaluated by DASH questionnaire and 
Gartland and Werley scoring system. They reported that $70 \%$ of the patients had good or excellent outcome. The need for the removal of plates or tendon rupture among these patients until the final follow up was not observed.

Farhan et al. [21] reviewing data of 24 patients with severe comminuted fracture of distal radius treated by double plating, reported complications such as tendon rupture, carpal tunnel syndrome, infection and non-union, in addition to the early removal of dorsal plate among four patients. Besides, they concluded that double plating has the advantages of early motion and good outcome.

We did not notice any clinical complications that necessitate more interventions among our study patients. On the contrary, radiological outcome showed no correlation to the clinical outcome in our study.

\section{Conclusion}

Complex distal intra-articular radial fractures can be treated either by external fixator or by locked pre-contoured plating. Surgical techniques are demanding and should be performed by skilled surgeons. Restoring the articular surface is essential for normal function of the wrist. The clinical outcome of plating versus external fixator treatment did not show significant difference in our study. The radiological outcome did not correlate with the clinical outcome. Further studies are needed to clarify the existing conflict in the treatment of complex distal intra-articular radial fractures.

\section{Conflicts of Interest}

The authors declare no conflicts of interest.

\section{References}

[1] Cooney III, W.P., Linscheid, R.L. and Dobyns, J.H. (1979) External Pin Fixation for Unstable Colles' Fractures. The Journal of Bone \& Joint Surgery, 61, 840-845. https://doi.org/10.2106/00004623-197961060-00006

[2] Wolfe, S.W., Pike, L., Slade III, J.F., et al. (1999) Augmentation of Distal Radius Fracture Fixation with Coralline Hydroxyapatite Bone Graft Substitute. Journal of Hand Surgery, 24, 816-827. https://doi.org/10.1053/jhsu.1999.0816

[3] Orbay, J.L. and Fernandez, D.L. (2002) Volar Fixation for Dorsally Displaced Fractures of the Distal Radius: A Preliminary Report. Journal of Hand Surgery, 27, 205-215. https://doi.org/10.1053/jhsu.2002.32081

[4] Musgrave, D.S. and Idler, R.S. (2005) Volar Fixation of Dorsally Displaced Distal Radius Fractures Using the 2.4-mm Locking Compression Plates. Journal of Hand Surgery, 30, 743-749. https://doi.org/10.1016/j.jhsa.2005.03.006

[5] Karnezis, I.A. and Fragkiadakis, E.G. (2002) Association between Objective Clinical Variables and Patient-Rated Disability of the Wrist. The Journal of Bone \& Joint Surgery, 84, 967-970. https://doi.org/10.1302/0301-620X.84B7.12673

[6] Anzarut, A., Johnson, J.A., Rowe, B.H., et al. (2004) Radiologic and Patient-Reported Functional Outcomes in an Elderly Cohort with Conservatively Treated Distal Radius Fractures. Journal of Hand Surgery, 29, 1121-1127. https://doi.org/10.1016/j.jhsa.2004.07.002

[7] Sarmiento, A., Pratt, G., Berry, N., et al. (1979) Colles' Fractures. Functional Bracing 
in Supination. The Journal of Bone \& Joint Surgery, 57, 311-317. https://doi.org/10.2106/00004623-197557030-00004

[8] McQueen, M.M. (1998) Redisplaced Unstable Fractures of the Distal Radius: A Randomised, Prospective Study of Bridging versus Non-Bridging External Fixation. The Journal of Bone \& Joint Surgery, 80, 665-669. https://doi.org/10.1302/0301-620X.80B4.8150

[9] Lee, H.D., Monsivais, J.J., Pomerance, J., Trenholm, J.A., Zelle, A.B., Evans, J.P., et al. (2013) Appropriate Use Criteria for Treatment of Distal Radius Fractures. AAOS Evidence-Based Medicine Unit 2013. http://www.aaos.org/aucapp

[10] Atroshi, I., Brogren, E., Larsson, G.U., et al. (2006) Wrist-Bridging versus NonBridging External Fixation for Displaced Distal Radius Fractures: A Randomized Assessor-Blind Clinical Trial of 38 Patients Followed for 1 Year. Acta Orthopaedica, 77, 445-453. https://doi.org/10.1080/17453670610046389

[11] Huang, T., Huang, C., Yu, J., et al. (2005) Operative Treatment of Intra-Articular Distal Radius Fractures Using the Small AO External Fixation Device. Journal of the Chinese Medical Association, 68, 474-478. https://doi.org/10.1016/S1726-4901(09)70077-2

[12] Grewal, R., MacDermid, C.J., Pope, J., et al. (2007) Baseline Predictors of Pain and Disability One Year Following Extra-Articular Distal Radius Fractures. HAND, 2, 104-111. https://doi.org/10.1007/s11552-007-9030-x

[13] Rozental, T.D., Blazar, P.E., Franko, O.I., et al. (2009) Functional Outcomes for Unstable Distal Radial Fractures Treated with Open Reduction and Internal Fixation or Closed Reduction and Percutaneous Fixation. A Prospective Randomized Trial. JBJS, 91, 1837-1846. https://doi.org/10.2106/JBJS.H.01478

[14] Kasapinova, K. and Kamiloski, V. (2011) Outcome Evaluation in Patients with Distal Radius Fracture Contributions. Macedonian Academy of Sciences and Arts, Section of Biological and Medical Sciences, 32, 231-246.

[15] Kettler, M., Kuhn, V., Schieker, M., et al. (2008) Do We Need to Include Osteoporosis in Today's Classification of Distal Radius Fractures? Journal of Orthopaedic Trauma, 22, S79-S82. https://doi.org/10.1097/BOT.0b013e318162ab36

[16] Dhainaut, A., Daibes, K., Odinsson, A., et al. (2014) Exploring the Relationship between Bone Density and Severity of Distal Radius Fragility Fracture in Women. Journal of Orthopaedic Surgery and Research, 9, 2-8. https://doi.org/10.1186/s13018-014-0057-8

[17] Fernandez, L.D. and Jupiter, B.J. (2002) Fractures of the Distal Radius A Practical Approach to Management. Springer Science + Business Media, LLC, New York, USA.

[18] De la Torre, M., Moreno, N., Luis, R., et al. (2006) Surgery of Distal Radius Fractures: Assessment of Results. Revista de Ortopedia y Traumatología, 50, 366-371.

[19] Ring, D., Prommersberger, K. and Jupiter, B.J. (2004) Combined Dorsal and Volar Plate Fixation of Complex Fractures of the Distal Part of the Radius. The Journal of Bone \& Joint Surgery, 68, 1646-1652. https://doi.org/10.2106/00004623-200408000-00007

[20] Day, S.C., Kamath, F.A., Makhni, E., et al. (2008) “Sandwich” Plating for Intraarticular Distal Radius Fractures with Volar and Dorsal Metaphyseal Comminution. HAND, 3, 47-54. https://doi.org/10.1007/s11552-007-9061-3

[21] Farhan, M.F.M., Wong, J.H.K., Sreedharan, S., et al. (2015) Combined Volar and Dorsal Plating for Complex Comminuted Distal Radial Fractures. Journal of Orthopaedic Surgery, 23, 19-23. https://doi.org/10.1177/230949901502300105 
Submit or recommend next manuscript to SCIRP and we will provide best service for you:

Accepting pre-submission inquiries through Email, Facebook, LinkedIn, Twitter, etc. A wide selection of journals (inclusive of 9 subjects, more than 200 journals)

Providing 24-hour high-quality service

User-friendly online submission system

Fair and swift peer-review system

Efficient typesetting and proofreading procedure

Display of the result of downloads and visits, as well as the number of cited articles Maximum dissemination of your research work

Submit your manuscript at: http://papersubmission.scirp.org/

Or contact ojo@scirp.org 